\title{
Genetic markers associated with antimalarial drug resistance and haemoglobin genotypes among malaria patients in Kaduna State, Nigeria
}

Gideon Yakusak Benjamin ( $\sim$ gideonbenjamin.y@gmail.com )

Ahmadu Bello University https://orcid.org/0000-0003-3887-4363

Helen Ileigo Inabo

Ahmadu Bello University

Hassan Isa Doko Muhammad

Ahmadu Bello University

Busayo 0 Olayinka

Ahmadu Bello University

\section{Research}

Keywords: Malaria, genes, haemoglobin, Plamodium, phylogenetic

Posted Date: August 10th, 2020

DOI: https://doi.org/10.21203/rs.3.rs-31076/v2

License: (c) (1) This work is licensed under a Creative Commons Attribution 4.0 International License. Read Full License 


\section{Abstract}

Background Malaria is a disease of public health concern in Nigeria and sub-Saharan Africa. The emergence of drug resistance, particularly among $P$. falciparum strains, has been a major contributor to the global burden of malaria. This research was aimed at detecting genetic markers ( $p f c r t, p f m d r 1, p f d h f r, p f d h p s$, pfatpase6) associated with antimalarial drug resistance and assessing the distribution of haemoglobin genotypes among malaria patients in of Kaduna State, Nigeria.

Methods Three hundred (300) blood samples were collected from consenting individuals attending selected hospitals, in the three senatorial districts of Kaduna State, Nigeria. A structured questionnaire was used to obtain relevant data from the study participants. The samples were screened for malaria parasites by microscopy and malaria rapid diagnostic test kit. Deoxyribonucleic acid was extracted from one third of the malaria positive samples, and Polymerase Chain Reaction (PCR) was used for detection of the drug resistance genes. Pfcrt, pfmdr1, pfdhfr, pfdhps and pfatpase6 genes were detected at expected amplicon sizes from the malaria positive samples. The pfatpase6 PCR amplicons were sequenced and a phylogenetic tree was created using MEGA X to determine their relatedness to published sequences.

Results Pfcrt (80\%) had the highest prevalence, followed by pfdhfr (60\%), pfmdr1 (36\%) and pfdhps (8\%). Pfatpase6 was also detected in $73.3 \%$ of the samples. The phylogenetic tree showed that all the pfatpase 6 gene sequences (both the ones from this study and those published in NCBI Genbank) had the same origin and were closely related. However, the sequences from NCBI Genbank were from one clade; arising from a common ancestor (monophyletic) thus they were more closely related to themselves, than to the pfatpase 6 sequences obtained in this study. Of all the malaria positive participants, those with $\mathrm{HbAA}(73 \%)$ haemoglobin genotype had the highest percentage followed by $\mathrm{HbAS}(23 \%), \mathrm{HbAC}(3 \%)$ and HbSS (1).

Conclusion We detected Plasmodium falciparum genes associated with drug resistance to commonly used antimalarials in the study area. Expression of these genes could have serious consequences in the treatment of malaria. The percentage of Plasmodium falciparum malaria was higher among persons with $\mathrm{HbAA}$ than those with $\mathrm{HbAS}, \mathrm{HbAC}$ and $\mathrm{HbS}$.

\section{Introduction}

Malaria is caused by intracellular parasites of the genus Plasmodium. It is transmitted through the bite of infected female Anopheles mosquito. Despite being preventable and treatable, malaria remains one of the major health problems in subSaharan Africa [1] even though there were encouraging reports that malaria morbidity and mortality were declining $[2,3]$.

Nearly half of the world's population was at risk of malaria in 2018 [4]. There was an estimated 228 million cases of malaria worldwide in 2018 which was an increase from the estimated 219 and 217 million cases of malaria in 2017 and 2016 respectively [5,4]. The estimated number of malaria deaths in 2018 stood at 405000 [4]. Six countries accounted for more than half of all malaria cases worldwide in 2018: Nigeria (25\%), the Democratic Republic of the Congo (12\%), Uganda (5\%), and Cote d'Ivoire, Mozambique and Niger (4\% each) [4]. The 10 highest burden countries in Africa reported increases in cases of malaria in 2017 compared with 2016. Of these, Nigeria, Madagascar, and the Democratic Republic of Congo had the highest reported increases, all greater than half a million cases [5].

Resistance to antimalarial agents arises because of the selection of parasites with genetic mutations or gene amplifications that confer reduced susceptibility [6]. Resistance genes continue to be selected in Plasmodium thereby causing resurgences in the disease incidence [7]. One of the main obstacles to malaria control is the ability of the parasites to develop resistance to administered anti-malarial drugs. The development of resistance to drugs poses the greatest threats to malaria control and results in increased malaria morbidity and mortality [8]. The emergence of drug resistance, particularly among $P$. falciparum strains, has been a major contributor to the global burden of malaria in the past three decades [9]. Resistance is the most likely explanation for the doubling of malaria-attributable child mortality in eastern and southern Africa [7,10,11].

Artemisinin-based combination therapy is the first-line therapy in Nigeria and most malaria endemic countries $[11,12)$. In 2005, Nigeria changed its antimalarial drug policy to artemisinin based combination therapy (ACT) [11]. However, recent 
gains in reducing the burden of malaria are threatened by the emergence of Plasmodium falciparum resistance to artemisinins. The current cornerstones in malaria treatment are artemisinin combination therapy for treatment of uncomplicated Plasmodium falciparum malaria [13] and sulfadoxine-pyrimehamine (SP) for intermittent preventive treatment of pregnant women. While resistance to SP is already established, there are evidence of decreased susceptibility or resistance to the ACT components; artemisinins and the key ACT partner drugs lumefantrine, amodiaquine and mefloquine [14]. Development of resistance to ACTs and aggravation of SP resistance could be devastating, as there are presently no further well established treatment options.

The prevalence of healthy carriers of the sickle cell gene ranges between $1 \%$ and $40 \%$ across Africa [15]. Nigeria has an estimated carrier prevalence of $6 \%$ to $24 \%$ [16]. An estimated 150000 children are born with sickle cell disease in Nigeria annually [17]. Indeed, resistance to Plasmodium falciparum is an important adaptive trait of human populations living in endemic areas [18]. Haemoglobin S (HbS) has become a stable polymorphism within malaria endemic regions, associated with a limited life expectancy among homozygous individuals who suffer from sickle cell disease, and an extended life expectancy of heterozygous individuals who are more likely to evade malaria [19]. HbAS is widely known to confer significant protection from severe and uncomplicated malaria [20] although underlying mechanisms are not precisely defined.

The resistance to different anti-malarial drugs is due to single nucleotide polymorphisms (SNPs) in different $P$. falciparum genes, including pfdhfr, pfdhps, pfcrt, pfatcase6, pfk13 and pfmdr1. The accumulation of SNPs in these parasites can produce in vivo resistance [21]. This stresses the importance of understanding the molecular mechanisms of resistance in order to prevent its emergence or spread [22]. This study was aimed at detecting genetic markers associated with antimalarial drug resistance and assessing the distribution of haemoglobin genotypes among malaria patients in of Kaduna State, Nigeria.

\section{Materials And Methods}

\section{Study area}

The study was conducted in selected general hospitals within the three Senatorial Districts of Kaduna State, Nigeria. Blood samples were collected from patients in Hajiya Gambo Sawaba General Hospital Zaria (Kaduna North Senatorial District), Barau Diko Teaching Hospital (Kaduna Central Senatorial District) and General Hospital Kafanchan (Kaduna South Senatorial district). Kaduna lies at latitude $10^{\circ} 20^{\prime}$ north and longitude $7^{\circ} 45^{\prime}$ east and covers an area of $45,711.2 \mathrm{~km}^{2}$. It has a population of $6,113,503$ and a population density of 130 people/ $\mathrm{km}^{2}$. It accounts for $4.3 \%$ of Nigeria's total population. Kaduna lies in the savanna ecological belt. It experiences a rainy (wet) season between April and October and a harmattan (dry and dusty) season between November and March. The area experiences an average annual rainfall of $1099 \mathrm{~mm}$ and average daily temperature of $28^{\circ} \mathrm{C}$. Malaria occurs all year round, with peaks during the middle to late rainy season [23].

\section{Study design}

The study was a cross-sectional study that lasted for six months (May to October 2018).

\section{Inclusion criteria and non-inclusion criteria}

All febrile patients presenting symptoms of malaria that were directed to the laboratory for malaria parasite (MP) test and gave consent were included. All patients directed to the laboratory for laboratory tests other than malaria test and those who did not give consent were non-inclusion.

\section{Sample size}

The sample size was determined using a prevalence of $22.4 \%$ [23] and the following formula as described by [24]: 
$\mathrm{n}=$ number of samples

$p=$ prevalence rate of previous study $=22.4 \%=0.224$

$z=$ standard normal distribution at $95 \%$ confidence limit $=1.96$

$d=a b s o l u t e$ desired precision of $5 \%=0.05$

$z=1.96$

$\mathrm{n}=\underline{1.96} \underline{\underline{2}} * \underline{0.224}(\underline{1-0.224})$.

$0.05^{2}$

$\mathrm{n}=\underline{3.8416 * 0.224 * 0.776}$

0.0025

$n=267$ samples

The sample size was increased to 300; 100 blood samples were collected from each hospital within the three senatorial districts.

\section{Administration of consent forms and structured questionnaire}

Consent forms and structured questionnaire were administered to consenting individuals who met the inclusion criteria. This was used to obtain bio-data and information relevant to this research.

\section{Sample collection and preparation of blood films}

Two milliliter $(2 \mathrm{ml})$ of venous blood was collected by a trained laboratory technician and transferred into an EDTA container. Thick and thin blood films were prepared immediately after the samples were collected according to the technique outlined by [25]. A drop of each blood sample was placed in the center of a grease-free clean glass slide, and spread immediately using a smooth edged slide spreader to make a thin film. The thin film was allowed to air dry before being fixed with methanol. The thick film was made by transferring a drop of blood to another clean slide and spread in such a way that it was possible to see (but not read through) newsprint, it was then allowed to dry properly. The blood films were stained using $10 \%$ Giemsa working solution for 30 minutes. After staining the blood films, they were allowed to air-dry [25].

\section{Examination of stained blood film slides}

The stained blood films were examined under the microscope using 100X objective lens after focusing. Presence of ring forms, trophozoites or gametocytes of Plasmodium falciparum or other Plasmodium sp was recorded as positive results. A blood smear was considered negative if no parasite was seen after 10 minutes of search or examination under 100X high power fields of microscope.

The prevalence of malaria was determined by the number of positives over the number of specimens collected.

Positivity rate $=\underline{\text { Number of positives }} \times 100$

Total number of samples

\section{Deoxyribonucleic Acid (DNA) extraction}


Total DNA was extracted from 25 of the 71 malaria positive blood samples using Zymo Research Quick-DNA ${ }^{\text {TM }}$ Miniprep Plus Kit, Irvine, California.

\section{Determination of haemoglobin genotype}

Cellulose acetate method of haemoglobin electrophoresis was carried out on all malaria positive samples as follows: A drop of blood from all malaria positive blood samples was placed on a clean white tile and mixed with three drops of water to lyse the red blood cells. With the aid of an applicator, the haemolysate was placed on a cellulose acetate paper. This was followed by electrophoresis in Tris buffer solution for 15 minutes at electromotive force of 250v. Haemolysates from blood samples of $\mathrm{Hb}$ AS and $\mathrm{AC}$ were run as controls [26].

\section{Primers used for Polymerase Chain reaction}

The genes and primer sequences used for the polymerase chain reaction are shown below in Table 1. The target genes were; Plasmodium falciparum resistance transporter ( $p f c r t)$ gene which is a single copy, 13-exon gene, localised on chromosome 7 and codes for a digestive vacuole trans-membrane protein, which plays a key role in chloroquine resistance. Plasmodium falciparum multidrug resistance transporter 1 (pfmdr1) gene which codes for a large 12 transmembrane domain ABCtransporter (PfMRP1), located in the parasite plasma membrane [27], Plasmodium falciparum dihydrofolate reductase ( $p f d h f r)$ gene (codes for $P$. falciparum dihydrofolate reductase enzyme), Plasmodium falciparum dihydropteroate synthase (pfdhps) gene which codes for dihydropteroate synthase enzyme of Plasmodium falciparum and Plasmodium falciparum atpase6 gene (pfatpase6).

Table 1: Primer sequences used for polymerase chain reaction

\begin{tabular}{|c|c|c|c|c|}
\hline Gene & Primer sequence & $\begin{array}{l}\text { Size } \\
\text { (bp) }\end{array}$ & SNPs (codons) & Reference \\
\hline \multirow[t]{2}{*}{ PfCrt } & F: GGAGGTTCTTGTCTTGGTAAAT & 315 & 391T/A,392G/C, 399G/T & [28] \\
\hline & R: ATATTGGTAGGTGGAATAGATTCT & & 400A/G,402T/A,404A/C (codons C72S, M74I,N75E, K76T) & \\
\hline \multirow[t]{3}{*}{ Pfmdr1 } & F: & 514 & 256A/T,257A/T (Codon N86Y/F) & \\
\hline & TGTTGAAAGATGGGTAAAGAGCAGA & & & \\
\hline & R: TCGTACCAATTCCTGAACTCACTT & & & \\
\hline \multirow[t]{2}{*}{ Pfdhps } & F: GATTCTTTTTCAGATGGAGG & 770 & 1482T/G,1483C/T/G,1486C/G,1794A/G,1918C/G,2013G/T/A, & \\
\hline & R: TTCCTCATGTAATTCATCTGA & & (codon S436A/F/C, A437G, K540E, A581G, A613S/T) & \\
\hline \multirow[t]{3}{*}{ Pfdhfr } & F: TGATGGAACAAGTCTGCGACGTT & 594 & 148T/C,152A/T,153T/C, 175T/C, 323G/A/C,490A/T (codons & \\
\hline & $\mathrm{R}:$ & & C50R,N511, C59R, S108, I164L) & \\
\hline & CTGGAAAAAATACATCACATTCATATG & & & \\
\hline \multirow[t]{2}{*}{ Pfapse6 } & F: AAAATAAATACCACATCAACACAT & 437 & 2306G/A (codon769N) & \\
\hline & R: TCAATAATACCTAATCCACCTAAA & & & \\
\hline
\end{tabular}

\section{Detection of genetic markers of Plasmodium falciparum}

The primer sequences in Table 1 were used to amplify pfcrt, pfmdr1, pfdhfr, pfdhps and pfatpaes 6 genes by multiplex PCR as follows: Multiplex PCR master mix cocktail was prepared by adding $3.0 \mu \mathrm{l}$ of the extracted DNA, $2.5 \mu$ l of $10 \mathrm{X}$ PCR buffer, $1.5 \mu \mathrm{l}$ of $50 \mathrm{mM} \mathrm{MgCl}_{2}, 1.0 \mu \mathrm{l}$ of $2.5 \mathrm{Mm}$ dNTPs, $1.0 \mu \mathrm{l}$ of Taq polymerase $(5 \mathrm{U} / \mu \mathrm{l}), 5 \mu \mathrm{l}$ of nuclease free water, $1.0 \mu \mathrm{l}$ each of $5 \mathrm{pMol}$ of each of the forward and reverse primers in table 1 to give a total volume of $25 \mu \mathrm{l}$. This was run using the following programme: Initial detauration at $94^{\circ} \mathrm{C}$ for 5 minutes followed by 9 cycles of denaturation at $94^{\circ} \mathrm{C}$ for 15 seconds, annealing at $65^{\circ} \mathrm{C}$ for 20 seconds, extension at $72^{\circ} \mathrm{C}$ for 30 seconds and another 35 cycles of denaturation at $94^{\circ} \mathrm{C}$ for 15 seconds, annealing at $55^{\circ} \mathrm{C}$ for 20 seconds, extension at $72{ }^{\circ} \mathrm{C}$ for 30 seconds, final extension at $72{ }^{\circ} \mathrm{C}$ for 7 minutes.

The PCR amplicons were separated by electrophoresis on a $1.5 \%(\mathrm{w} / \mathrm{v})$ agarose gel stained with ethidium bromide. The gel was visualised on UV transilluminator gel imaging system and system photographed, band positions were determined and compared to molecular weight markers. 


\section{Amplification and Sequencing of pfatpase6 Gene}

The pfatpase 6 gene was amplified using the pfatpase 6 primers in Table 1 above as follows: The master mix cocktail was prepared by adding $2.0 \mu \mathrm{l}$ of $100 \mathrm{ng} / \mu \mathrm{l}$ DNA, $2.5 \mu \mathrm{l}$ of $10 x$ PCR buffer, $1.5 \mu \mathrm{l}$ of $50 \mathrm{mM} \mathrm{MgCl}_{2}, 1.0 \mu \mathrm{l}$ of DMSO, $2.0 \mu \mathrm{l}$ of $2.5 \mathrm{Mm}$ dNTPs, $0.15 \mu$ l of Taq Polymerase $(5 \mathrm{U} / \mu \mathrm{l}), 1.0 \mu \mathrm{l}$ forward primer, $1.0 \mu \mathrm{l}$ reverse primer and $13.85 \mu \mathrm{l}$ nuclease free water to make a total of $25 \mu \mathrm{l}$. This was run using the following programme: Nine cycles of initial denaturation at $94^{\circ} \mathrm{C}$ for 15 minutes, denaturation at $94^{\circ} \mathrm{C}$ for 40 seconds, annealing at $60^{\circ} \mathrm{C}$ for 120 seconds, extension at $72^{\circ} \mathrm{C}$ for 40 seconds. This was followed by another 35 cycles of denaturation at $94^{\circ} \mathrm{C}$ for 40 seconds, annealing at $50^{\circ} \mathrm{C}$ for 120 seconds, extension at $72^{\circ} \mathrm{Cfor} 40$ seconds, final extension at $72^{\circ} \mathrm{C}$ for 10 minutes. The PCR amplicons were separated by electrophoresis and visualised on UV transilluminator gel imaging system (gel documentation unit), after which gel pictures were taken from which band positions were determined and compared to molecular weight markers.

\section{Sequencing of pfatpase6 gene}

Amplicon purification was done using QiaQuick DNA gel extraction kit (Qiagen, Hilden, Germany) according to the manufacturer's instructions. Five to $10 \mu \mathrm{l}$ of purified PCR products were used to prepare the sequencing mix using the $\mathrm{ABI}$ Prism BigDye Terminator Cycle Sequencing Ready Reaction Kit V3.1. (Applied Biosystem, Foster City, CA, USA).

\section{Phylogenetic analysis}

The multiple sequence alignment programme Clustal W was used to obtain an optimal nucleotide sequence alignment file after comparing with sequences deposited in GenBank. Phylograms were obtained by MEGA X based on aligned nucleotide sequences.

\section{Results}

Only Plasmodium falciparum was detected in this study, and a total prevalence of $23.7 \%(71 / 300)$ was obtained. The agarose gel electrograph in Figure 1 shows the amplification of $p f c r t, p f m d r 1, p f d h f r$ and $p f d h p s$ by multiplex PCR. Analysis of the number and percentages of the genes amplified by multiplex PCR (Table 2) showed that out of the 25 DNA samples screened, there were 20 (80\%) pfcrt, 9 (36\%) pfmdr1, 15 (60\%) pfdhfr and 2 (8\%) pfdhps genes amplified by multiplex PCR. The gel electrophoresis of the resultant multiplex PCR products indicated that they were of the expected sizes. Some nonspecific amplifications were observed for the samples. Eleven out of the 15 DNA samples analysed (73.3\%) showed amplification of the pftpase6 gene (Figure 2). The phylogenetic tree showing the relatedness between the pfatpase6 sequences in this study and sequences obtained from the NCBI GenBank is shown in Figure 3. All the pfatpase6 sequences showed close relationship as compared to the outgroup (Plasmodium_vivax_E1-E2_ATPase/hydrolase). Participants with haemoglobin genotype AA had the highest prevalence of malaria (73\%), followed by those with haemoglobin genotypes AS (23\%), AC (3\%) and SS (1\%) (Figure 4).

Figure 1: Agarose gel electrograph for the detection of pfcrt (315bp), pfmdr1 (514bp), pfdhfr (594bp), and pfdhps (770bp) genes

Key: Lane $\mathrm{M}=$ Molecular weight marker (50bp), Lanes 1-25= Plasmodiun falciparum positive samples, bp= base pairs

Table 2: Analysis of the number and percentages of the genes amplified by multiplex PCR

\begin{tabular}{llll}
\hline Genes & No. examined & Frequency & \% Prevalence \\
\hline Pfcrt & 25 & 20 & 80 \\
Pfmdr1 & 25 & 9 & 36 \\
Pfdhfr & 25 & 15 & 60 \\
Pfdhps & 25 & 2 & 8 \\
\hline
\end{tabular}

Page 6/13 
Key: pfcrt=Plasmodium falciparum chloroquine resistance transporter, pfmdr1=Plasmodium falciparum multidrug resistance transporter I, pfdhfr= Plasmodium falciparum dihydrofolate reductase, $p f d h p s=$ Plasmodium falciparum dihydropteroate synthase

\section{Figure 2: Agarose gel electrograph of amplified pfatpase6 gene}

Key: Lane M: Molecular weight marker (50bp), Lanes 1-15: Plasmpdium falciparum positive samples, bp= base pairs

\section{Figure 3. Phylogenetic tree (neighbor joining tree) of pfapase6 sequences}

Key: Plasmodium falciparum ATpase6_1 to 6 = sequences from this study, the other pfatpase 6 sequences were obtained from NCBI, and Plasmodium_vivax_E1-E2_ATPase/hydrolase = Outgroup.

\section{Figure 4: Haemoglobin electrophoresis patterns of malaria positive participants in the study area}

\section{Discussion}

The primers used in this study were designed by Zhang et al.[28] to amplify regions containing single nucleotide polymorphisms (SNPs) covering genetic markers reported to be associated with the resistance of Plasmodium falciparum to some of the most commonly used antimalarial drugs such as chloroquine, mefloquine, amodiaquine, sulfadoxinepyrimetamine and artemether. Pfcrt, pfmdr1, pfdhfr, pfdhps genes were detected at expected amplicon sizes from the malaria positive samples in this study. Pfcrt (80\%) had the highest prevalence, followed by pfdhfr (60\%), pfmdr1 (36\%) and pfdhps (8\%). The presence of these genes, if expressed, will pose a significant danger to the management and control of malaria [5].

The wide spread of chloroquine-resistant parasites prompted the WHO to recommend Artemisinin-based Combination Therapy for the treatment of malaria in endemic regions. Studies from the Republic of Congo describing the prevalence of polymorphisms in pfcrt conferring chloroquine resistance showed that all the Plasmodium falciparum isolates were carrying the pfcrt alleles $[29,30]$.

The current study successfully amplified segments of pfcrt as well as pfmdr1 carrying known mutations associated with chloroquine resistance. The high prevalence of the pfcrt shows that chloroquine resistance is still very likely in the studied population despite its withdrawal as first line drug for the treatment of uncomplicated malaria in Nigeria in 2005 [31,32]. In their report, Sidhu et al. [33] provided conclusive evidence that pfcrt mutations increased susceptibility to artemisinin and quinine, and minimally affected amodiaquine activity.

In this study, pfdhfr (60\%) had a higher prevalence than pfdhps (8\%) which suggests that there are more Plasmodium falciparum parasites carrying the mutant pfdhfrgene in the study population than those carrying the pfdhps genes. Mutations in the pfdhfr and pfdhps genes have been associated with resistance to pyrimethamine and sulfadoxine respectively [34]. In Nigeria, sulfadoxine is given in combination with pyrimethamine as sulfadoxine-pyrimethamine (SP) to pregnant women during intermittent preventive treatment (IPT) of pregnant women [35]. The high prevalence of pfdhfr gene mutations may be due to wide usage of Pyrimethamine in combination with Sulfadoxine for the treatment of pregnant women in Nigeria. This indicates possible resistance to pyrimethamine and consequently reduce the efficacy of SP as a combination therapy. The possession of more than one drug resistance gene in some of the Plasmodium falciparum parasites in this study may increase their resistance to different antimalarials, and probably lead to high rate of treatment failure with these drugs.

In this study, only the portion of pfatpase6 gene carrying the 2306G/A SNP at codon S769N was amplified. Maslachah et al. [36] reported in their study that all the resistant Plasmodium falciparum isolates contained pfatpase6 S769N mutation which is associated with artemisinin resistance. A similar finding was also reported by Jambou et al. [37] and Jung et al. [38]. 
The phylogenetic tree revealed the similarities and relatedness between pfatpase 6 sequences in this study and the reference sequences. The phylogenetic tree showed that all the pfatpase6 gene sequences (both the ones from this study and those from NCBI) had the same origin and were closely related. However, the sequences from NCBI were from one clade; arising from a common ancestor (monophyletic) thus they were more closely related than to the pfatpase6 sequences from this study.

Haemoglobin genotype is known to influence the prevalence of malaria in endemic areas [39]. The results of this study revealed that $73 \%$ of the malaria positive participants had the haemoglobin genotype AA (HbAA), which was higher than the percentages in the other genotypes (HbAS [23\%]) and $\mathrm{HbAC}$ [3\%]). This is similar to the reports of Albiti and Nsiah [40] and Akanbi [39]. The prevalence of participants with $\mathrm{HbAS}$ and $\mathrm{HbAC}$ were quite low compared to $\mathrm{HbAA}$. This suggests that individuals with $\mathrm{HbAS}$ and $\mathrm{HbAC}$ are probably able to resist malaria better than $\mathrm{HbAA}$. This is in agreement with the findings of Aidoo et al. [41], Ayi et al. [42], Williams et al. [43], Albiti and Nsiah [40] and Archer et al. [44]. In another study by Williams et al. [45], HbAS was $50 \%$ protective against mild clinical malaria, $75 \%$ protective against admission to the hospital for malaria, and almost $90 \%$ protective against severe or complicated malaria. The level of susceptibility to malaria has been reported to be higher in individuals with $\mathrm{HbAA}$ when compared with those with $\mathrm{HbAS}$ and $\mathrm{HbAC}$, thus, the high frequency of $\mathrm{HbAC}$ and $\mathrm{HbAS}$ in malaria endemic areas has been attributed to a decrease in malaria morbidity and mortality in malaria endemic areas $[46,44]$. The protective role displayed by $\mathrm{HbAC}$ and $\mathrm{HbAS}$ in malaria infection is as a result of reduced cytoadhesion of infected red blood cell to microvasculature and impaired rosette formation as a result of the presence of abnormal PfEMP1 antigen on HbAC and HbCC [47].

Earlier studies $[48,49]$ had associated low oxygen tension in HbAS RBCs with impairment in the invasion and growth of Plasmodium falciparum parasites in the HbAS red blood cells (RBCs) which causes infected RBCs to sickle under low oxygen tension and lead to their premature destruction in the spleen, thus, reducing parasitaemia and providing protection. In a more recent study by Archer et al. [44], they reported that resistance to Plasmodium falciparum in sickle cell erythrocytes is driven by oxygen dependent-growth inhibition. Their experiments showed that low oxygen (1\% oxygen concentration) indeed stalled the growth of Plasmodium falciparum and no DNA replication was evident at that oxygen concentration.

Rosette formation (binding of Plasmodium falciparum infected RBCs) which is thought to lead to microcirculatory obstruction in cerebral malaria was found to be impaired in $P$. falciparum infected HbAS RBCs under deoxygenated conditions; this may be due to increased sickling of the RBCs in deoxygenated condition or reduced expression of erythrocyte surface adherence protein [50]. Decreased rosette formation and the resulting decreased circulatory obstruction might contribute to protection against severe malaria in HbAS.

The protective effect of $\mathrm{HbC}$ may result from a reduced ability of Plasmodium falciparum to grow and multiply in RBCs containing $\mathrm{HbC}$ [51]. $\mathrm{HbC}$ exerts its protection through a specific effect on cytoadherence, mediated by the altered display of surface expressed parasite proteins [52,53].

It has been reported that subjects with HbSS appear to be less susceptible than normal to developing malaria but are highly susceptible to the catastrophic consequences of malaria particularly severe anaemia if they do become infected with the parasite $[54,55]$.

\section{Conclusion}

The Plasmodium falciparum parasites in the study population have the drug resistance genes; pfcrt, pfmdr1, pfdhfr, pfdhps and pfatpase6. The expression of these genes will cause resistance to the commonly used antimalarial drugs, which by extension will lead to a significant public health challenge in the treatment and control of malaria within the study area. Plasmodium falciparum parasites carrying two or more drug resistance genes may pose a significant danger to malaria chemotherapy. The high frequency of HbAA genotype in malaria positive participants implies that people having the aforementioned haemoglobin type are less protected from malaria than those having $\mathrm{HbAS}, \mathrm{HbAC}$ and $\mathrm{HbSS}$. This may not 
be far from the fact that $\mathrm{HbAS}$ and $\mathrm{HbAC}$ have been reported in many studies to provide protection against malaria, especially falciparum malaria.

\section{Declarations}

\section{Ethics approval and consent to participate}

Ethical approval was obtained from the Health Research Ethics Committee of Kaduna State Ministry of Health as well as Barau Diko Teaching Hospital Health Research Ethics Committee (BDTH-HREC); HREC Reference number:18-00016.

\section{Consent for publication}

All participants gave consent.

\section{Availability of data and materials}

The datasets generated and/or analysed during the current study are available from the corresponding author on reasonable request.

\section{Competing interest}

The authors declare that they have no competing interests.

\section{Funding}

None

\section{Author's contributions}

GYB designed the study, conducted the laboratory and data analysis, and prepared the manuscript. HII, HIDM and BOO supervised the research, read and approved the manuscript.

\section{Acknowledgements}

We appreciate the contributions of Dr. Elijah E. Ella and other staff members of Microbiology Department, Ahmadu Bello University Zaria. We also acknowledge the Bioscience Centre, International Institute for Tropical Agriculture where the molecular analysis was conducted.

\section{References}

1. Kebede S, Aseffa A, Medhin G, Berhe N, and Velavan TP. Re-evaluation of microscopy confirmed Plasmodium falciparum and Plasmodium vivax malaria by nested PCR detection in southern Ethiopia. Malaria Journal 2014, 13: 48.

2. Nyarango PM, Gebremeskel T, Mebrahtu G, Mufunda J, Abdulmumini U, Ogbamariam, A, Kosia A, Gebremichael A, Gunawardena D, Ghebrat Y, Okbaldet Y. A steep decline of malaria morbidity and mortality trends in Eritrea between 2000 and 2004: the effect of combination of control methods. Malaria Journal 2006, 5:333

3. Ouji, M., Augerea, J.M., Paloque, L. and Benoit-Vical F: Plasmodium falciparum resistance to artemisinin-based combination therapies: A sword of Damocles in the path toward malaria elimination. Parasite 2018, 25:24.

4. WHO: World malaria report 2019.Retrieved from http://www.who.int/news-room/feature-stories/detail/world-malariareport-2019 (2019)

5. WHO: Retrieved from https://www.who.int/news-room/fact-sheets /detail /malaria (2018).

6. WHO: World Malaria Report 2010. Geneva: World Health Organization (2010). 
7. Hedrick PW. Resistance to malaria in humans: the impact of strong, recent selection. Malaria Journal 2012, 11:349.

8. Centers for Disease Control and Prevention. Malaria: Drug resistance. Retrieved from https://www.cdc.gov/malaria/malaria-worldwide/reeduction/drug_resistance. html (2018).

9. White NJ. (2004). Antimalarial drug resistance. Journal of Clinical Investigation 2004,113:1084-1092.

10. Korenromp EL, Williams BG, Gouws E, Dye C, Snow RW. Measurement of trends in childhood malaria mortality in Africa: an assessment of progress toward targets based on verbal autopsy. Lancet Infectious Disease 2003, 3: 349-58.

11. Okoro RN, Jamiu MO. The cross sectional evaluation of the use of artemisinin-based combination therapy for treatment of malaria infection at a tertiary hospital in Nigeria. Journal of Tropical Medicine 2018, 6: 2025858.

12. Lin Z, Zaw MT. (2015). Molecular Determinants of Artemisinin Resistance in k13 Gene of Plasmodium falciparum, British Microbiology Research Journal, 9(4): 1-8.

13. Banek K, Web EL, Smith SJ, Chandramohan D, Staedke SG. Adherence to treatment with artemeher-lumefantrine or amodiaquine-artesunate for uncomplicated malaria in children in Sierra Leone: a randomized trial. Malaria Journal, 2018, 17:222.

14. WHO: Guidelines for the treatment of malaria, second edition. Geneva, World Health Organisation (2010).

15. Anie KA, Egunjobi FE, Akinyanju OO. Psychosocial impact of sickle cell disorder: Perspectives from a Nigerian setting. Global Health 2010; 6:2.

16. Weatherall DJ, Clegg JB. Inherited haemoglobin disorders: An increasing global health problem. Bull World Health Oragnisation. 2001; 79:704-12.

17. WHO:Sickle cell anaemia. Report by the secretariat. Fifty ninth world Health Assembly.2008

18. Lusingu JP, Vestergaard LS, Mmbando BP, Drakeley CJ, Jones C, Akida J, Savaeli ZX, Kitua AY, Lemnge MM, Theander TG. Malaria morbidity and immunity among residents of villages with different Plasmodium falciparum transmission intensity in North-Eastern Tanzania. Malaria Journal 2004, 3:26.

19. Bougouma EC, Tiono AB, Ouedraogo A, Soulama I, Diarra A, Yaro JB, Ouédraogo E, Sanon S, Konaté AT, Nébié I, Watson NL, Sanza M, Dube TJ, Sirima SB. Haemoglobin variants and Plasmodium falciparum malaria in children under five years of age living in a high and seasonal malaria transmission area of Burkina Faso. Malaria Journal 2012, 11:154.

20. Verra F, Bancone G, Avellino P, Blot I, Simpore J, Modiano D. Haemoglobin C and S in natural selection against Plasmodium falciparum malaria: a plethora or a single shared adaptive mechanism? Parassitologia 2007, 49:209-213.

21. Berzosa P, Esteban-Cantos A, García L, González V, Navarro M, Fernández T, Romay-Barja M, Herrador Z, Rubio JM, Ncogo P, Santana-Morales M, Valladares B, Riloha M, Benito A. Profile of molecular mutations in pfdhfr, pfdhps, pfmdr1, and pfcrt genes of Plasmodium falciparum related to resistance to different anti-malarial drugs in the Bata District (Equatorial Guinea). Malaria Journal 2017, 16: 28.

22. Dahlström S. Role of PfATPase6 and pfMRP1 in Plasmodium falciparum resistance to antimalarial drugs. Unit of Infectious Diseases, Department of Medicine, Karolinska University Hospital, Karolinska Institutet, Stockholm, Sweden. Published by Karolinska Institutet. Printed by E-print. ISBN 978-91-7409-481-7 (2009).

23. Aliyu MM, Nasir IA, Umara YA, Vanstawaa AP, Meduguc JT, Emeribed AU, Amadue DO. Prevalence, risk factors, and antimalarial resistance patterns of falciparum plasmodiasis among pregnant women in Kaduna metropolis, Nigeria. Tzu Chi Medical Journal 2017, 29 (2): 98-103.

24. Naing L, Winn T, Rusli BN. Practical issues in calculating the sample size for prevalence studies. Archives of Orofacial Sciences 2006, 1: 9-14.

25. Cheesebrough M. District laboratory practice in tropical countries part 1, second edition. New york: Cambridge University Press. 245-249 (2009).

26. Egesie OJ, Joseph DE, Isiguzoro I, Egesie UG. Glucose-6-phosphate dehydrogenase (G6PD) activity and deficiency in a population of Nigerian males resident in Jos. Nigerian Journal of Physiological Sciences 2008, 23(1-2):9-11. 
27. Klokouzas A, Wu CP, van Veen HW, Barrand MA, Hlandky SB. cGMP and glutathione-conjugate transport in human erythrocytes. European Journal of Biochemistry 2003, 270 (18): 3696-708.

28. Zhang GQ, Guan YY, Sheng HH, Zheng B, Wu S, Xiao HS, Tang LH. Multiplex PCR and oligonucleotide microarray for detection of single-nucleotide polymorphisms associated with Plasmodium falciparum drug resistance. Journal of Clinical Microbiology 2008, 46 (7), 2167-2174.

29. Mayenge PI, Ndounga M, Davvy MM, Tandou N, Ntoumi F. In vivo chloroquine resistance and prevalence of the $p f c r t$ codon 76 mutation in Plasmodium falciparum isolates from the Republic of Congo. Acta Tropica 2005, 95.219-225.

30. Ndounga M, Tahar R, Bosko LK, Casimiro PN, Malonga DA, Ntoumi F. Therapeutic efficacy of sulfadoxine-pyrimethamine and the prevalence of molecular markers of resistance in under 5 year olds in Brazzaville, Congo. Tropical Medicine and International Health 2005, 12:1164-1171.

31. Ogundipe S. Chloroquine making a comeback against malaria? Retrieved from https://www.vanguardngr.com/2012/10/chloroquine-making-a-comeback-against- malaria (2012).

32. Olawande O. Eleven years after years after ban, Chloroquinen still used for malaria treatment in Nigeria. Premium Times. Retrieved from https://www.premiumtimesng.com/health/health-features/227663-investigation-eleven-years-banchloroquine-still-used-malaria-treatment -nigeria.html (2017).

33. Sidhu AB, Verdier-Pinard D, Fidock DA. Chloroquine resistance in Plasmodium falciparum malaria parasites conferred by Pfcrt Science 2002, 298: 210-213.

34. Lo AC, Faye B, Ba E, Cisse B, Tine R, Abiola A, Ndiaye M, Ndiaye JLA, Ndiaye D, Sokhna C, Gomis JF, Dieng Y, Faye O, Ndir O, Milligan P, Cairns M, Hallet R, Sutherland C, Gaye O. Prevalence of molecular markers of drug resistance in an area of seasonal malaria chemoprevention in children in Senegal. Malaria Journal 2013, 12:137.

35. FMOH: National Antimalaria Treatment Policy. Abuja Nigeria: Nationa Malaria and Vector Control Division, Federal Ministry of health (2005).

36. Maslachah L, Dachlan YP, Nidom CA, Fitri LE. Experimental models point mutations in Plasmodium falciparum pfatpase6 gene exposed to recurring artemisinin in vitro. Veterinary Medicine International Conference 2017, $422-435$.

37. Jambou R, Legrand E, Niang M, Khim N, Lim P, Volney B, Ekala MT, Bouchier C, Esterre P, Fandeur T, Mercereau-Puijalon O. Resistance of Plasmodium falciparum field isolates to in-vitro artemether and point mutations of the SERCA-type PfATPase6. Lancet 2005, 366: 1960-1963.

38. Jung M, Kim H, Nam KY, No KT. Three-dimensional structure of Plasmodium falciparum Ca2+-ATPase (PfATPase6) and docking of artemisinin derivatives to PfATPase6. Bioorganic and Medical Chemistry Letter 2005, 15: 2994-2997.

39. Akanbi OM. Influence of haemoglobin genotype on malaria parasite density and anti-msp- $1_{19}$ lgG (antibody) response in pregnant women and birth weight of neonates. FUTA Journal of Research in Sciences 2015, 11(1): 46-54.

40. Albiti AH, Nsiah K. Comparative haematological parameters of HbAA and HbAS genotype children infected with Plasmodium falciparum malaria in Yemen. Hematology 2014, 19 (3): 169-174.

41. Aidoo M, Terlouw DJ, Kolczak MS, McElroy PD, ter Kuile FO, Kariuki S, Nahlen BL, Lal AA, Udhayakumar V. (2002). Protective effects of the sickle cell gene against malaria morbidity and mortality. Lancet 2002, 359: 1311-1312.

42. Ayi K, Turrini F, Piga A, Arese P. Enhanced phagocytosis of ring-parasitized mutant erythrocytes. A common mechanism that may explain protection against falciparum malaria in sickle trait and beta-thalassemia trait. Blood 2004,104 (10):3364-71.

43. Williams TN, Mwangi TW, Roberts DJ, Alexander ND, Weatherall DJ, Wambua S, Kortok M, Snow RW, Marsh K. An immune basis for malaria protection by the sickle cell trait. PLoS Medicine 2005, 2 (5): e128.

44. Archer NM, Petersen N, Clark MA, Buckee CO, Childs LM, Duraisingh MT. Resistance to Plasmodium falciparum in sickle cell erythrocytes is driven by oxygen dependent- growth inhibition. Proceedings of the National Academy of Sciences of the United States of America 2018,115 (28): 7350-7355. 
45. Williams TN, Mwangi TW, Wambua S, Alexander ND, Kortok M, Snow RW, Marsh K. Sickle cell trait and the risk of Plasmodium falciparum malaria and other childhood diseases. Journal of Infectious Diseases 2005, 192 (1): 178-186.

46. Uneke CJ, Sunday-Adeoye I, Iyare FE, Ugwuja El, Duhlinska DD. Impact of maternal Plasmodium falciparum and haematological parameters on prevalency and its outcome in southeastern Nigeria. Journal of Vector Borne Disases 2007, 44: 285-290.

47. Fairhurst RM, Bess CD, Krause Abnormal PfEMP1/knob display on Plasmodium falciparum-infected erythrocytes containing haemoglobin variants: fresh insights into malaria pathogenesis and protection. Microbes Infect 2012, 14 (10): 851-862.

48. Luzzatto L, Nwachuku-Jarrett ES, Reddy S. Increased sickling of parasitised erythrocytes as mechanism of resistance against malaria in the sickle-cell trait. Lancet 1970, 1: 319-321.

49. Friedman MJ, Roth EF, Nagel RL, Trager W. The role of haemoglobins C, S, and Nbalt in the inhibition of malaria parasite development in vitro. American Journal of Tropical Medicine and Hygiene 1979, 28: 777-780.

50. Cholera R., Brittain NJ, Gillrie MR, Lopera-Mesa TM, Diakite SA, Arie T, Krause MA, Guindo A, Tubman A, Fujioka H, Diallo DA, Doumbo OK, Ho M, Wellems TE, Fairhaurst RM. Impaired cytoadherence of Plasmodium falciparum-infected erythrocytes containing sickle haemoglobin. Proceedings of the National Academy of Sciences of the United States of America 2008,105: 991-996.

51. Fairhurst RM, Baruch DI, Brittain NJ, Ostera GR, Wallach JS, Hoang HL, Hayton K, Guindo A, Makobongo MO, Schwartz OM, Tounkara A, Doumbo OK, Diallo DA, Fujioka H, Ho M, Wellems TE. Abnormal display of PfEMP-1 on erythrocytes carrying haemoglobin C may protect against malaria. Nature 2005, 435: 1117-1121.

52. Brittain NJ, Erexson C, Faucette L, Ward J, Fujioka H, Wellems TE, Fairhurst RM. Non-opsonising aggregates of IgG and complement in haemoglobin C erythrocytes. British Journal Haematology 2007, 136: 491-500.

53. Cyrklaff M, Sanchez CP, Kilian N, Bisseye C, Simpore J, Frischknecht F, and Lanzer M. Haemoglobins S and C interfere with actin remodeling in Plasmodium falciparum-infected erythrocytes. Science 2011, 334: 1283-1286.

54. McAuley CF, Webb C, Makani J, Macharia A, Uyoga S, Opi DH,... Williams TN. High mortality from Plasmodium falciparum malaria in children living with sickle cell anemia on the coast of Kenya. Blood 2010, 116: 1663-1668.

55. Williams TN, Obaro SK. Sickle cell disease and malaria morbidity: A tale with two tails. Trends in Parasitology 2011, 27:315-320.

\section{Figures}

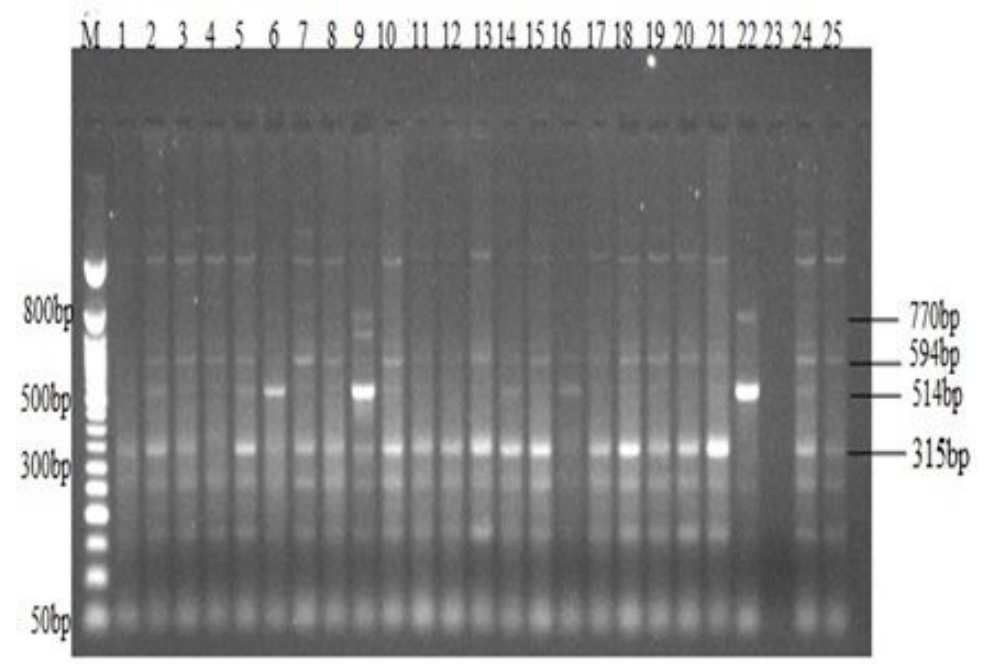

Figure 1 
Agarose gel electrograph for the detection of pfcrt (315bp), pfmdr1 (514bp), pfdhfr (594bp), and pfdhps (770bp) genes

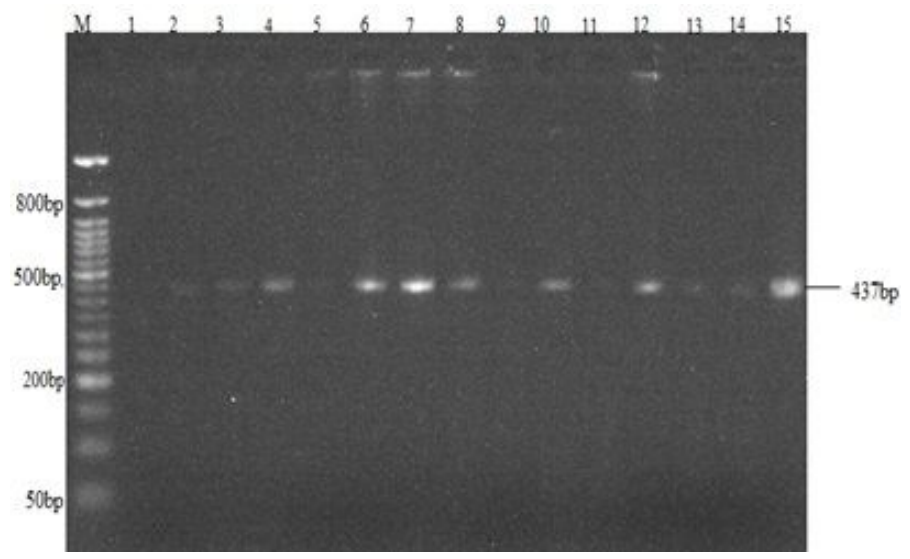

\section{Figure 2}

Agarose gel electrograph of amplified pfatpase6 gene Key: Lane M: Molecular weight marker (50bp), Lanes 1-15: Plasmpdium falciparum positive samples, $b p=$ base pairs

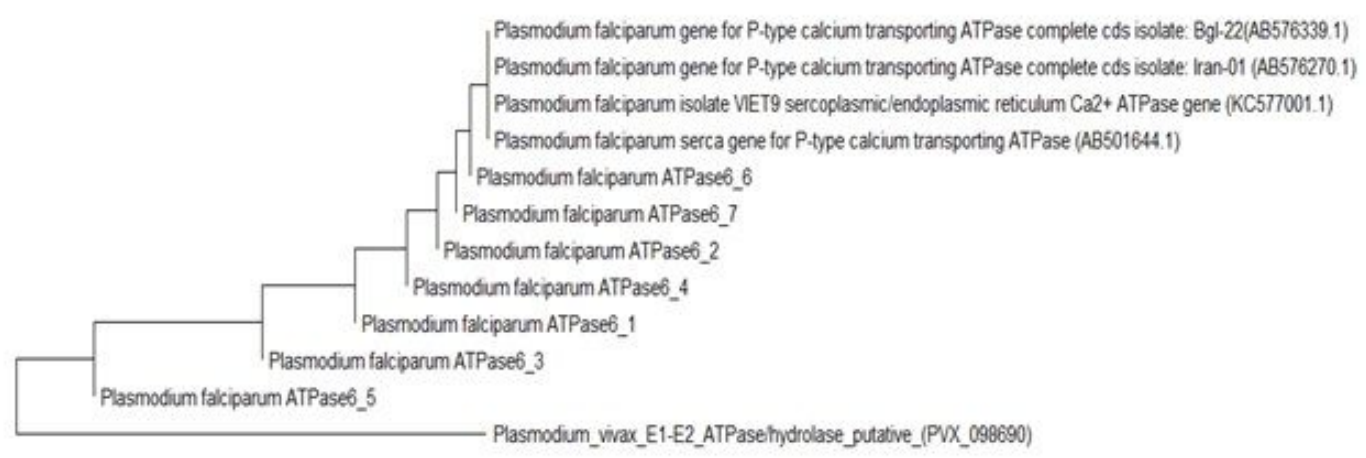

0.50

\section{Figure 3}

Phylogenetic tree (neighbor joining tree) of pfapase6 sequences Key: Plasmodium falciparum ATpase6_1 to $6=$ sequences from this study, the other pfatpase6 sequences were obtained from NCBI, and Plasmodium_vivax_E1-E2_ATPase/hydrolase = Outgroup.

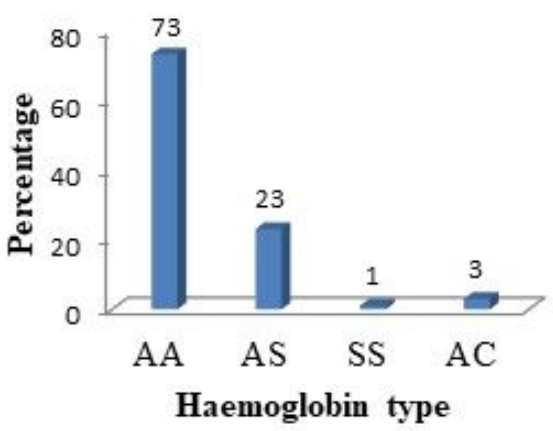

\section{Figure 4}

Haemoglobin electrophoresis patterns of malaria positive participants in the study area 